\title{
Natural Disaster
}

\section{Tiara McIntosh, Doctoral Student}

Liberty University, United States

URL:http://dx.doi.org/10.19044/ejes.s.v6a5

\begin{abstract}
This article presents the natural disaster and how it affects children over the world. When there is a natural disaster occurring such as hurricanes, tornadoes, flooding, it can affect not only the family but the children as well. The children are often left to relocate, live with other family members, or separated from their parents. Natural disasters can lead to externalize behaviors with kids. The Journey of Hope, a school-based group work intervention for children and early adolescents who have experienced a collective trauma such as a natural disaster can assist kids with externalizing behaviors. Through the use of group work interventions such as group problem solving and experiential and reflective learning, children and early adolescent work toward improving protective factors to assist them in their recovery.
\end{abstract}

Keywords: Natural disaster, school interventions, trauma and children.

\section{Introduction:}

Since 2010, more than 700 natural disasters have affected more than 450 million people worldwide including more than 66.5 million each year" (International Monetary Fund, 2012). When a child is impacted by these traumatic events, it can affect a child's communication, emotional, and physical well-being. The risk factors are life-changing for children and their communities (Garrett et al., 2007; Kataoka, Rowan, \& Hoagwood, 2009; Walsh, 2007). Improving a child's capacity to improve and overcome these traumatic events requires new methods and predictions regarding natural disasters (Gall, Borden, Emrich, \& Cutter, 2011).

\section{School interventions for children Impacted by Collective Trauma}

The social impact on children impacted by a traumatic event such as natural disaster can be devastatingly contributing to "emotional strains and affecting a child's physical and emotional growth" (LaGreca \& Prinstein, 2002; Silverman et al., 20008). The emotional turmoil may be displayed through re-experiencing the event, hyperarousal, externalizing symptoms or 
internalizing symptoms (Wang et al., 2006, p. 364). Research has shown that within a year after the traumatic event, children are often at a heightened risk for anxiety, nervousness, anger, depression, and acting out at school and/or at home (Kataoka et al., 2003; Liu et al., 2011). Longer- term issues may include an increased risk for depending on an illegal substance, anxiety-related issues, depression, and suicide attempts (Dube et al., 2001; McFarlane \& Van Hoof, 2009: Putnam, 2006; Strauss, Dapp, Anders, von Rentein-Kruse, \& Schmidt, 2011). Given the negative psychological series of traumatic events can have on young people, broadly accessible techniques that address their mental health necessities are the main priority (Peek, 2008).

School-based mental health interventions are particularly appropriate given access to young people in schools (Weist, Rubin, Moore, Adelshiem, \& Wrobel, 2007). Not surprisingly, the majority of current services in mental health care delivered through schools (Burns et al., 1995; Weist et al., 2007). Although school may be the correct place to offer mental health services less clear is the most effective or relevant approaches to providing broad-based techniques to young people who have experienced a lot of trauma such as a natural disaster.

Cognitive-behavioral Interventions have, to date, been considered the gold standard of posttrauma school-based mental health interventions. Silverman and colleagues (2008) examined 21 studies on evidence-based psychosocial interventions for children and adolescents who displayed mental symptoms related to traumatic events and found that the majority were treatment-oriented and cognitive-behavioral focused. Cognitive Behavioral Intervention for Trauma in Schools (CBITS), Trauma-Focused Cognitive Behavioral Treatment (TF-CBT), Trauma-Focused Coping in Schools (TFC), and Grief and Trauma Intervention for Children are all based on evidencebased cognitive-behavioral activities. These treatment-oriented programs are designed for young people who exhibit signs or have been treated for posttraumatic stress (Silverman et al., 2008).

\section{The Journey of Hope Background}

The Journey of Hope was initially developed in response to a postHurricane Katrina gang fight in New Orleans middle school after a crisis counselor reached out to save the children, an international organization involved in Hurricane Katrina recovery efforts. The fights were associated with the difficulties the youth experienced as a result of the hurricane including separation from family, displacement to new schools and neighborhoods, and negative adjustment to the context of post-Katrina New Orleans, including externalizing behaviors among young people. The youth involved the conflict were also among those who were most adversely affected by the storm. They came from low poverty neighborhoods where many had 
been previously been already engaged to community violence which put them at a higher risk for a variety of chronic traumas, including community violence, abuse, and neglect (Jones, 2007; Peek, 2008).

\section{The Intervention Model}

The Journey of Hope has evolved into a set of three programs that supports children between the ages 5 and 13 (Kindergarten to Grade 8) in normalizing emotions they may experience after. Disaster and develop positive coping skills through team engagement strategies, creative arts, and reading. The intervention model is organized into eight one-hour-long sessions, with groups of eight to 10 children that are generally implemented 2 times a week over a month within a school term or in a summer camp. The group leaders work with teachers and social workers to create diverse groups of eight to 10 students ranging from those who may be experiencing more difficulties with those who are coping well. If a child is exhibiting extreme externalizing behavior, he or she may be unable to function in a Journey of Hope group but would require a more one-on-one therapeutic program (Powell $\&$ Blanchet-Cohen, 2014). The core tenets of the program are to help youth understand and normalize key emotions, identify triggers and stressors, and create a positive coping mechanism to deal with these emotions dysfunction (Save the Children, 2009).

\section{Strengths-based approach}

The strength-based approach of the intervention involves providing children with positive resources to understand and cope with emotions caused by traumatic situations. According to Saleeby (1996), the strengths-based model in social work focuses on the "capacities, talents, competencies, possibilities, visions, values and hope" (p. 296) rather than their disorders or pathologies. The Journey of Hope supports youth by normalizing the pain they experience after trauma by building positive coping skills and helping them recognize internal and external resources that may support them. The intervention model helps a child address and overcome a traumatic event through building outside connection such as promoting a positive relationship with caring adults, building problem-solving skills, and promoting healthy peer relationships (Masten \& Obradovic, 2006; Stevenson \& Zimmer, 2005).

\section{Group Work Techniques}

Research has shown that children who work in cooperative and collaborative group environments tend to have enhanced preschool attitudes and academic achievement (Kutnick, Ota, \& Berdondini, 2008). Fawcett and Previous researcher posited that through group work young people can learn from, help each other, and collectively resolve conflict. Group work 
approaches in the Journey of Hope include the use of rituals, experiential learning, group problem solving, and reflective learning (Powell, BlanchetCohen, 2014).

\section{Use of Rituals}

The use of rituals is the main key to the intervention model. As Malekoff (2004) noted, rituals can build cohesion and increase group distinctiveness. In the Journey of Hope rituals service, in each group meeting, to improve sharing and increase comfort among the group members. For instance, each meeting has a similar opening activity that provides structure and consistency at the beginning of the group meeting. The younger kids gather around a parachute, whereas the older children sit in chairs in a circle. The group leader begins with a check-in and introduces the topic of the day (Holleran ,Steiker, \& Powell, 2012).

\section{Experiential learning}

Experiential learning has been defined as "the involvement of learners in concrete activities that enable them to experience what they are learning about and have the opportunity to reflect on those activities (Silberman, 2007, p.2)." Through experiential activities group, participants may not only gain a cognitive understanding of a concept but also develop behavioral and affective skills to understand and internalize knowledge. Learning experiences involve more than simply hearing and reading, they consist of many "sensory, information-receiving systems such as moving, touching, and visualizing (Middleman \& Goldberg-Wood, 1990, pp. 2-3)." Experiential learning is a central component of that involves role-play, cooperative games, and art activities integrated throughout.

Experiential learning is the main key of the Journey of Hope with roleplays, cooperative games, and art activities integrated throughout. This enables participants to learn about emotions and coping through didactic presentation and hands-on activities, to comprehend common post-disaster emotions and devise healthy coping strategies.

\section{Discussion}

The Journey of Hope offers young people an approach to process emotions associated with a collective trauma such as a natural disaster. The effectiveness of group work to enable young people to learn from and embrace each other in ways that man not be succeeded through individual therapy, alone (Fothergrill \& Peek, 2004; Peek, 2008).

An initial evaluation conducted in New Orleans found that students who participated in the Journey of Hope exhibited improved self-esteem, increased the ability to identify their feelings, and a strengthened attachment 
to their peers and the group workers (Blanchet-Cohen \& Nelems, 2013). Following evaluations in New Zealand and Alabama have yielded similar finds and also indicated that the program helped reduce classroom disruptions and other externalizing behaviors such as anxiety and depression (Holleran Steiker \& Powell, 2011; Powell, 2011). The format and focus on Journey of hope fills in a gap, complementing conventional treatment approaches that have a more limited reach and focus. Providing social and emotional support to groups of children in schools who have experienced a collective trauma can also support community resilience in the aftermath of a natural disaster (Barrett, Ausbrooks, \& Martinez-Cosio, 2008; MacNeil \& Topping, 2009; Ronan \& Johnsoton, 2005). Further, given the broad-based nature of the Journey of Hope, the technique may be pertinent in addressing other traumatic events such as a school shooting or act of terrorism. It may also be adapted as a preventative measure to help children verbalize emotions and learn how to effectively put some of the stressors encountered in day-to-day life.

Regarding sustainability and transferability of Journey of Hope, a key consideration is identifying group works who possess a combination of knowledge and skills in strengths-based mental health and group work. In situation, where the school faculty and other staff have also experienced trauma, the school social worker or counselor may be overwhelmed with the demands around helping rebuild the school community and providing individuals care to more traumatized students, not to mention their mental health. This suggests that Journey of Hope may need to be delivered by experienced mental health professionals who work outside of the school. It is very vital to build a close relationship with the school to collaborate programming and to figure out the most effective group composition and size (Powell \& Blanchet-Cohen, 2014).

Toseland and Rivas (2009) explained that the group should be structured so that members can cooperate and accomplish its purpose and goals. It is encouraged to collaborate with the administration at the school so that group workers know each group member's background and needs before they are assigned to the intervention. Further, it is suggested that the group worker be aware of each member background such as disciplinary issues, mental health diagnoses prior to commencing the group and that the group comprises a mix of students ranging from those who may be exhibiting more difficulties to those who are coping better. It is vital to note that if a child is exhibiting extreme emotional behavior and is unable to function in the group, the Journey of Hope may not be appropriate. Indeed, there are limitations to Journey of Hope for participants who exhibit either acute and/or chronic trauma from a disaster or related events, and who are so distressed that they may be unable to function in a group setting and, perhaps, will require an individualized, targeted mental health intervention. 


\section{Conclusion}

The Journey of Hope contributes to the field of post-disaster group work by offering a fairly simple model that helps group members build coping skills using a strength-based approach. Through the use of group work, the intervention builds children's internal and external resources to help them move forward after a collective trauma, such as a natural disaster. By not focusing specifically on the traumatic event, rather on common emotions and reactions that may subsequently arise, the Journey of Hope seeks to inspire children. Given the growing risk of natural disaster globally, one can expect an increase in demand for programs such as the Journey of Hope that equips young people with healthy strategies to build resilience and enhance their capacity to cope with current and future life stressors (Powell \& BlanchetCohen, 2014).

\section{References:}

1. Barrett, E. J., Ausbrooks, C. Y. B., \& Martinez-Cosio, M. (2008). The school as a source of support for Katrina-evacuated youth. Children, Youth and Environments, 18(1), 202-235.

2. Blanchet-Cohen, N., \& Nelems, R. (2013). A child-centered evaluation of a psychosocial program: Promoting children's healing, safety and well-being in post-disaster contexts. Children, Youth and Environments, 23(1), 23-42

3. Boon, H. J., Cottrell, A., \& King, D. (2016). Disasters and social resilience: A bioecological approach. Abingdon, Oxon;New York, N.Y;: Routledge. doi:10.4324/9781315678726

4. Boon, H.J. (2014a), 'Disaster Resilience in a Flood-Impacted Rural Australian Town', Natural Hazards, vol. 71, no. 1, pp. 683-701.

5. Burns, B., Costello, E., Angold, A., Tweed, D., Stangl, D., Farmer, E. , \& Erkanli, A. (1995). Children's mental health service use across service sectors. Health Affairs, 14(3), 147-159.

6. Dale, A., Vella, K., Cottrell, A., Pert, P., Stephenson, B., Boon, H., King, D., White- house, H., Hill, R., Babacan, H. and Gooch, M. 2011, 'Conceptualising, Evaluating and Reporting Social Resilience in Vulnerable Regional and Remote Communities Facing Climate Change in Tropical Queensland'. MTSRF Transition Project Final Report, Marine and Tropical Sciences Research Facility, Cairns, Australia.

7. Dube, S. R., Anda, R. F., Felitti, V. J., Chapman, D. P., Williamson, D. F., \& Giles, W. H. (2001). Childhood abuse, household dysfunction, and the risk of attempted suicide throughout the life span. Journal of the American Medical Association, 286(24), 3089-3096. doi:10.1001/jama.286.24.3089 
8. Fothergill, A., \& Peek, L. A. (2004). Poverty and disasters in the United States: A review of recent sociological findings. Natural Hazards, 32(1), 89-110.

9. Gall, M., Borden, K. A., Emrich, C. T., \& Cutter, S. L. (2011). The unsustainable trend of natural hazard losses in the United States. Sustainability, 3(11), 2157-2181.

10. Garrett, A., Grant, R., Madrid, P., Brito, A., Abramson, D., \& Redlener, I. (2007). Children and megadisasters: lessons learned in the new millennium. Advances in Pediatrics, 54(1), 189-214. doi:10.1016/j.yapd.2007.03.011

11. Holleran Steiker, L., \& Powell, T. (2012). The Journey of Hope curricula: Building resilience after a natural disaster. Washington, DC: Save the Children U.S.

12. International Monetary Fund. (2012). Natural disasters hitting more people, becoming more costly. Retrieved from http://www.imf.org.ezproxy.liberty.edu/external/pubs/ft/survey/ so/2012/new101012a.htm

13. Jones, J. M. (2007). Exposure to chronic community violence resilience in African American children.Journal of Black Psychology, 33(2), 125-149.

14. Kataoka, S., Stein, B., Jaycox, L., Wong, M., Escudero, P., Tu, W. ... Fink, A. (2003). A school-based mental health program for traumatized Latino immigrant children. Academy of Child and Adolescent Psychiatry, 42(3), 311-318.

15. Kataoka, S., Rowan, B., \& Hoagwood, K. (2009). Bridging the divide: In search of common ground in mental health and education research and policy. Psychiatric Services,60(11), 1510-1515. doi:10.1176/appi.ps.60.11.1510

16. Kutnick, P., Ota, C., \& Berdondini, L. (2008). Improving the effects of group working in classrooms with young school-aged children: Facilitating attainment, interaction and classroom activity. Learning and Instruction, 18(1), 83-95.

17. LaGreca, A., \& Prinstein, M. (2002). Hurricanes and earthquakes. In W. LaGreca, E.Silverman, E. M. Vernberg \& M. Roberts (Eds.), Helping children cope with disasters and terrorism (pp. 107138). Washington, DC: American Psychological Association.

18. Liu, M., Wang, L., Shi, Z., Zhang, Z., Zhang, K., \& Shen, J. (2011). Mental health problems among children one-year after Sichuan earthquake in China: A follow-up study. PloS One, 6(2), 293-300. 
19. MacNeil, W., \& Topping, K. (2009). Crisis management in schools: evidence based. Journal of Educational Enquiry, 7(1), 64-94.

20. Masten, A., \& Obradovic, J. (2006). Competence and resilience in development. Annals of the New York Academy of Sciences, 1094(1), 13-27. doi:10.1196/annals.1376.003

21. McFarlane, A. C., \& Van Hooff, M. (2009). Impact of childhood exposure to a natural disaster on adult mental health: 20-year longitudinal follow-up study. British Journal of Psychiatry, 195(2), 142-148

22. Middleman, R., \& Goldberg-Wood, G. (1990). Skills for direct practice in social work. New York, NY: Columbia University Press.

23. National Registry of Evidence-based Programs and Practices. (2012). SAMHSA's National Registry of Evidence-based Programs and Practices.

Retrieved from http://www.nrepp.samhsa.gov/Index.aspx

24. Peek, L. (2008). Children and disasters: Understanding vulnerability, developing capacities, and promoting resilience - An introduction. Children, Youth and Environments, 18(1), 1-29. doi:10.7721/chilyoutenvi.18.1.00

25. Powell, T. (2011). The Journey of Hope Curricula: Building resilience after a natural disaster. Christchurch, New Zealand: Save the Children

26. Powell, T., \& Blanchet-Cohen, N. (2014). The journey of hope: A group work intervention for children who have experienced a collective trauma. Social Work with Groups, 37(4), 297-313. doi:10.1080/01609513.2013.873884

27. Putnam, F. W. (2006). The impact of trauma on child development. Juvenile and Family Court Journal,57(1), 1-11. doi:10.1111/j.1755-6988.2006.tb00110.x

28. Ronan, K., \& Johnston, D. (2005). Promoting community resilience in disasters: The role for schools, youth, and families. New York, NY: Springer.

29. Saleeby, D. (1996). The strengths perspective in social work practice: Extensions and cautions. Social Work, 41(3), 296-305.

30. Save the Children. (2009). The elementary Journey of Hope manual. Washington, DC:

31. Silberman, M. L. (Ed.). (2007). The handbook of experiential learning. San Francisco, CA: Wiley.

32. Silverman, W. K., Ortiz, C. $\quad$ D., Viswesvaran, C., Burns, B. J., Kolko, D. J., Putnam, F. W., \& AmayaJackson, L. (2008). Evidence-based psychosocial treatments for children and adolescents exposed to traumatic events. Journal of Clinical Child \& Adolescent Psychology, 37(1), 156-183 
33. Stevenson, F., \& Zimmerman, M. (2005). Adolescent resilience: A framework for understanding healthy development in the face of risk. Annual Review of Public Health, 26, 399-419. doi:10.1146/annurev.publhealth.26.021304.144357

34. Strauss, K., Dapp, U., Anders, J., von Renteln-Kruse, W., \& Schmidt, S. (2011). Range and specificity of war-related trauma to posttraumatic stress; depression and general health perception: Displaced former World War II children in late life. Journal of Affective Disorders, 128(3), 267-276. doi:http://dx.doi.org.ezproxy.liberty.edu/10.1016/j.jad.2010.07.009

35. Toseland, R., \& Rivas, R. (2009). An introduction to group work practice (6th ed.). Boston, MA: Pearson Education.

36. Walsh, F. (2007). Traumatic loss and major disasters: Strengthening family and community resilience. Family Process, 46(2), 207-227. doi:10.1111/j.1545-5300.2007.00205.x

37. Wang, Y., Nomura, Y., Pat Horenczyk, R., Doppelt, O., Abramovitz, R., Brom, D.,\& Chemtob, C. (2006). Association of direct exposure to terrorism, media exposure to terrorism, and other trauma with emotional and behavioral problems in preschool children. Annals of the New York Academy of Sciences, 1094(1), 363-368. doi:10.1196/annals.1376.051

38. Weist, M.D., Rubin, M., Moore, E., Adelshiem, S.,\& Wrobel, G. (20 07). Mental health screening in schools. Journal of School Health, 77(2), 53-58. 